\title{
Kinetic investigation of styrene emulsion polymerization with surface-active polyelectrolytes as emulsifier, 1 Kinetic study
}

\author{
Satoshi Kato ${ }^{1,2}$ *, Kiyoshi Suzuki ${ }^{2}$, Mamoru Nomura ${ }^{2}$ \\ ${ }^{1}$ Department of Chem. \& Biol. Engineering, Fukui National College of Technology, \\ Sabae, Fukui 916-8507, Japan; Fax +81-778-62-3415; kato@fukui-nct.ac.jp \\ ${ }^{2}$ Department of Materials Science \& Engineering, University of Fukui, Fukui 910- \\ 8507, Japan; Fax +81-776-27-8767; suzuki+ , nomuram+ @matse.fukui-u.ac.jp
}

(Received: October 16, 2004; published: May 21, 2005)

\begin{abstract}
A copolymer of methyl methacrylate and methacrylic acid to be used as a polymeric surfactant was synthesized by emulsifier-free semi-batch emulsion copolymerization. Emulsion polymerization of styrene was carried out at $50^{\circ} \mathrm{C}$ utilizing the ammonium salt of the copolymer as the polymeric emulsifier and potassium persulfate as the initiator, respectively. Both the number of polymer particles produced and the rate of polymerization were proportional to the 0.6 power of the initial emulsifier concentration, to the 0.4 power of the initial initiator concentration, and independent of the initial monomer concentration, respectively. These relationships are almost the same as those observed in the emulsion polymerization of styrene conducted using conventional surfactants like sodium dodecyl sulfate as the emulsifier and potassium persulfate as the initiator.
\end{abstract}

\section{Introduction}

It is well-known that emulsion polymerization enables the formation of polymer emulsions containing high solid content with low viscosity by using water as an environment friendly dispersion medium. A typical emulsion polymerization consists of water, monomer, water-soluble initiator and low-molecular-weight surfactant as emulsifier. The resulting polymer emulsion is directly used as a film-forming material, i.e., water-based paint, coating, adhesive etc. However, film formation by emulsion prepared by emulsion polymerization with a conventional surfactant as the emulsifier is inhibited by remaining surfactant and the resulting polymer film sometimes shows a rather hygroscopic nature and low water resistance. Furthermore, a polymer emulsion stabilized by low-molecular-weight surfactants has poor stability when mixed with several kinds of organic solvents, other polymeric resins and pigments. Various attempts have been pursued to avoid these problems. For examples, polymerizable surfactants [1-4], surface-active monomers [5] and polymeric surfactants [6-10] were used for these purposes. It is also well known that polymeric surfactants such as amphiphilic polymers are often used in emulsion polymerization to provide functional properties for the resultant polymer emulsion. Thus, polymeric surfactants have been applied for emulsion polymerizations because of their advantage to provide unique properties for the resultant polymer emulsions. 
In the emulsion polymerization of sparingly water-soluble monomers with conventional surfactants as emulsifiers, particle nucleation is believed to occur inside the emulsifier micelles since the micelles can solubilize not only such monomers, but also oligomeric radicals produced in the water phase. If polymeric surfactants are used for emulsion polymerization in place of conventional surfactants, they are also known to form a kind of aggregates that can solubilize monomers and oligomeric radicals, so that they could provide loci for the initiation of emulsion polymerization. The properties of polymeric surfactant aggregates are similar to those of conventional emulsifier micelles. However, the size and solubilization ability of these aggregates are different from those of conventional emulsifier micelles [10]. Therefore, the behaviour and the role of polymeric surfactant aggregates in emulsion polymerization may be expected to be somewhat different from those of conventional emulsifier micelles.

Kuo and Chen [10] carried out the emulsion polymerization of styrene (St) by using the sodium salt of poly(dodecyl acrylate-co-acrylic acid) as emulsifier, where they used both a water soluble initiator, potassium persulfate (KPS), and an oil-soluble initiator, 2,2'-azoisobutyronitrile (AIBN). They found in both initiator systems that polymer particles with bimodal particle size distributions were formed. They, therefore, concluded that these bimodal particle size distributions indicated that the polymerization loci might be both in the monomer droplets and in the polymeric surfactant aggregates because these are of comparative size.

Kim et al. [11] carried out an extensive study of the emulsion polymerization of St using the sodium salt of poly(styrene-co-a-methylstyrene-co-acrylic acid) as emulsifier and KPS as initiator, respectively. They found that the polymer particles produced with this polymeric surfactant were of very small size with a unimodal particle size distribution. Furthermore, they found that the rate of polymerization and the particle size were both dependent on the degree of neutralization of the polymeric surfactant.

As shown above, the kinetics of emulsion polymerization conducted with polymeric surfactants as emulsifier is not necessarily well understood yet at the present stage. The aim of this article is, therefore, to report on the detailed kinetic behaviour of the emulsion polymerization of St with a polymeric surfactant, ammonium salt of poly(methyl methacrylate-co-methacrylic acid) (poly(MMA-co-MAA), as emulsifier and potassium persulfate as initiator, respectively.

\section{Experimental part}

\section{Materials}

Commercially available MMA, MAA and St monomers were purified by distillation under nitrogen atmosphere. Commercial 2-ethylhexyl thioglycolate (2EHTG), potassium persulfate (KPS), sodium hydrogen sulfite (SHS) and sodium dodecyl sulfate (SDS) were of extra pure grade and were used without further purification. lon-exchanged and distilled (DDI) water was used in all experiments.

\section{Synthesis of polymeric surfactant}

Poly(MMA-co-MAA) was synthesized at $80^{\circ} \mathrm{C}$ by employing a semi-batch emulsifierfree emulsion copolymerization process. This is because semi-batch emulsion 
copolymerization under monomer-starved condition is well known to produce copolymers with comparatively constant composition, molecular weight and copolymer composition distribution (CCD) [12,13]. The molecular weight of the copolymer was controlled by adjusting the amount of chain transfer agent (2EHTG) added. The recipe is given in Tab.1. Aqueous KPS solution prepared by using DDI water was first charged into the reaction vessel and then, the mixture of MMA, MAA and 2EHTG was continuously fed into the reaction vessel kept at $80^{\circ} \mathrm{C}$ during the first $120 \mathrm{~min}$. Further, the reactor was maintained at $85^{\circ} \mathrm{C}$ for another $120 \mathrm{~min}$ in order to complete the polymerization and then, $1.5 \mathrm{~g}$ of SHS was added to decompose the residual initiator completely. Finally, aqueous ammonium solution was added to dissolve the resultant copolymer latex produced. The $\mathrm{pH}$ of the polymeric surfactant solution was adjusted to 7 . The molecular weight of poly(MMA-co-MAA) was determined at $40^{\circ} \mathrm{C}$ by gel permeation chromatography (GPC). Tetrahydrofuran (THF) was used as the eluent at a flow rate of $0.5 \mathrm{~cm}^{3} / \mathrm{min}$. Calibration was performed with standard polystyrene samples. Weight-average $\left(M_{\mathrm{w}}\right)$ and number-average $\left(M_{\mathrm{n}}\right)$ molecular weights of the polymeric surfactant thus produced were 4600 and 2300 , respectively.

Tab. 1. Recipe for the synthesis of poly(MMA-co-MAA)

$\begin{array}{ccc}\text { DDI water } & 1200 \mathrm{~g} & \\ \text { KPS } & 5.0 \mathrm{~g} & \\ \text { MMA } & 390 \mathrm{~g} & (75.3 \mathrm{~mol}-\%) \\ \text { MAA } & 110 \mathrm{~g} & (24.7 \mathrm{~mol}-\%) \\ \text { 2EHTG } & 40 \mathrm{~g} & \end{array}$

\section{Pyrene fluorescence measurement}

The existence of surfactant aggregates in aqueous poly(MMA-co-MAA) ammonium salt solution was confirmed by pyrene fluorescence measurement [14-16]. Fluorescence spectra were obtained using pyrene as a fluorescence probe at $25^{\circ} \mathrm{C}$. Aqueous polymeric surfactant solutions with various concentrations were prepared, and pyrene was added to the solutions so that its concentration was $5 \cdot 10^{-5} \mathrm{~mol} / \mathrm{dm}^{3}$. These solutions were stirred for $24 \mathrm{~h}$ and then filtered off to remove an undissolved portion of pyrene. All the aqueous solutions thus prepared for fluorescence measurements were maintained at $\mathrm{pH}$ 7.0. These solutions were subjected to pyrene fluorescence measurement at $25^{\circ} \mathrm{C}$.

\section{Emulsion polymerization}

Batch emulsion polymerizations of St were carried out in a $500 \mathrm{~cm}^{3}$ cylindrical glass reactor with a dished bottom, equipped with a paddle-type impeller with $45^{\circ}$-pitched four-blade stirrer. The reactor was first charged with desired amounts of monomer, emulsifier, and DDI water, a small portion of which was put aside for preparing an aqueous initiator solution. Then, the dissolved oxygen was purged by bubbling highly pure nitrogen gas (purity $>99.999 \%$ ) through the reaction mixture for about 20 min. The polymerization was started by pouring the aqueous initiator solution, which had been previously deoxygenated with the nitrogen gas and stored in a dropping funnel, into the reaction mixture. In all experiments, the reaction temperature was kept within $50 \pm 0.5^{\circ} \mathrm{C}$ using a thermostated water bath. 
During the polymerization, about $5 \mathrm{~g}$ of latex sample was taken from the reactor and poured into a flask containing $50 \mathrm{~cm}^{3}$ methanol as precipitant. The precipitated polystyrene was filtered off with a G3 glass crucible and dried overnight in an oven at $60^{\circ} \mathrm{C}$. The dried polymer sample was weighed to calculate the monomer conversion. Particle size was measured using a transmission electron microscope (TEM). The number of polymer particles produced was calculated as follows [17]:

$$
N_{\mathrm{T}}=\frac{6 M_{0} X_{\mathrm{M}}}{\pi \rho_{\mathrm{p}}{\overline{d_{v}}}^{3}} \quad{\overline{d_{v}}}^{3}=\frac{\sum n_{i} d_{\mathrm{p} i}{ }^{3}}{\sum n_{i}}
$$

where $N_{\mathrm{T}}$ is the number of polymer particles per $\mathrm{cm}^{3}$ water, $\bar{d}_{v}$ the volume-average diameter, $M_{0}$ the amount of monomer initially charged per $\mathrm{cm}^{3}$ water, $X_{M}$ the monomer conversion, and $\rho_{p}$ the density of the polymer $\left(1.05 \mathrm{~g} / \mathrm{cm}^{3}\right)$.

\section{Results and discussion}

\section{Confirmation of aggregate formation in polymeric surfactant solution}

There are five peaks in emission spectra of pyrene, and the emission intensities of the first $(374 \mathrm{~nm})$ and of the third peak $(385 \mathrm{~nm})$ are known to be sensitive to the microenvironment of pyrene. Thus, the intensity ratio of pyrene emission at $374 \mathrm{~nm}$ to that at $385 \mathrm{~nm}\left(I_{1} / I_{3}\right)$ has been used to monitor the aqueous-solution behaviour of conventional and polymeric surfactants [14-16]. A higher $I_{1} / l_{3}$ value means greater polarity of the environment around pyrene. A decreasing $I_{1} / I_{3}$ with increasing emulsifier concentration indicates the formation of a microenvironment with lower polarity, which corresponds to the formation of polymeric surfactant aggregates. Therefore, the formation of polymeric surfactant aggregates like micelles can be detected by plotting $I_{1} / I_{3}$ versus the concentration of aqueous polymeric surfactant solution. Fig. 1 shows $I_{1} / I_{3}$ measured in both aqueous polymeric surfactant and SDS solutions with various concentrations.

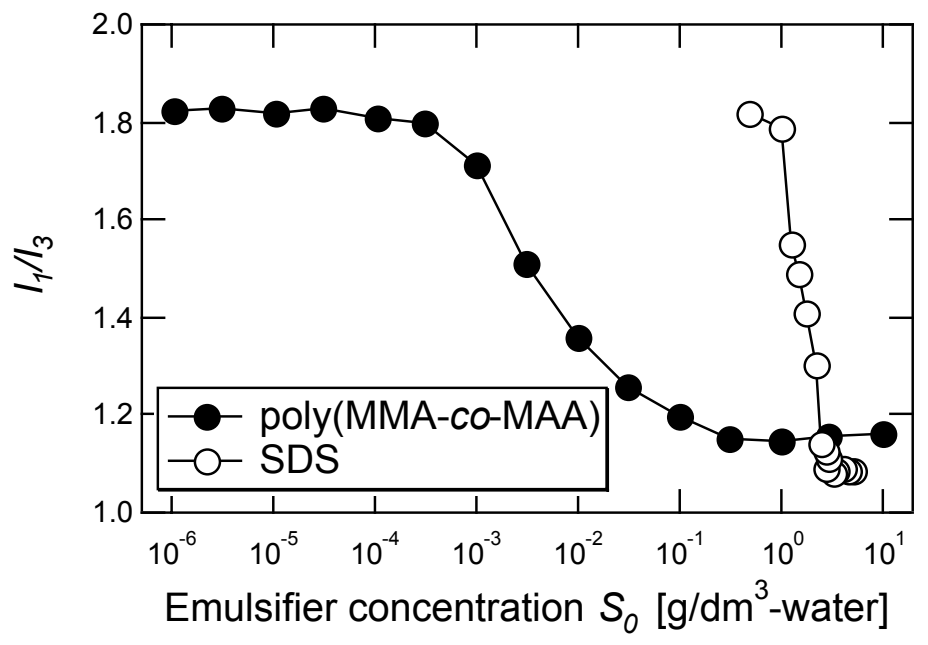

Fig. 1. Concentration dependence of $I_{1} / l_{3}$ of pyrene fluorescence in aqueous polymeric surfactant and SDS solutions

When the polymeric surfactant concentration is below $10^{-4} \mathrm{~g} / \mathrm{dm}^{3}$ in water, $I_{1} / I_{3}$ remains constant at a value of 1.8 , which is close to that in pure water, indicating that there are no aggregates formed. In the concentration region from $10^{-4}$ to $0.1 \mathrm{~g} / \mathrm{dm}^{3}$, 
the $I_{1} / I_{3}$ value decreases drastically to 1.13 . The inflection point for SDS seen at 2.5 $\mathrm{g} / \mathrm{dm}^{3}$ is in good agreement with the literature value of the critical micelle concentration (CMC) of aqueous SDS solution [18]. On the other hand, the inflection point seen at around $0.1 \mathrm{~g} / \mathrm{dm}^{3}$ for the aqueous polymeric surfactant solution indicates the formation of surfactant aggregates like micelles. The critical concentration forming aggregates in the aqueous polymeric surfactant solution, $0.1 \mathrm{~g} / \mathrm{dm}^{3}$, is considerably lower than $2.5 \mathrm{~g} / \mathrm{dm}^{3}$ as observed in the aqueous SDS solution. The reason for this may be that polymeric surfactants form intramolecular hydrophobic aggregates. This tendency is almost the same as that observed by Kuo et al., when they used polymeric surfactants such as poly(dodecyl acrylate-co-acrylic acid) sodium salt [10].

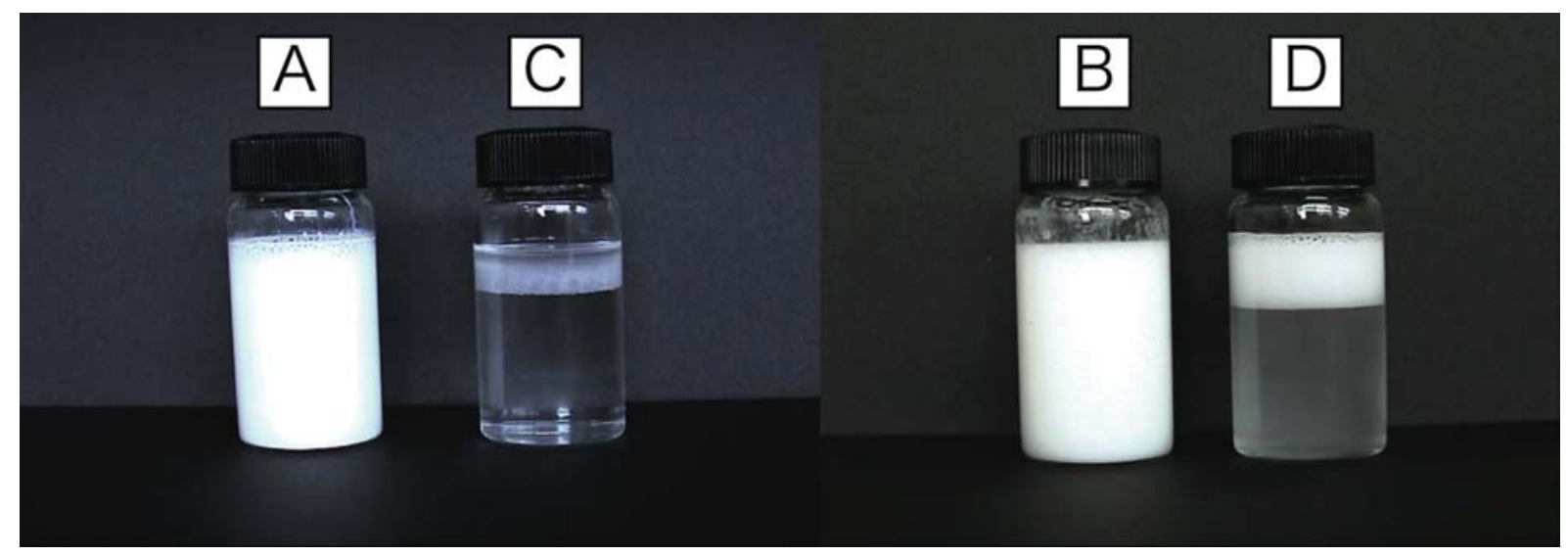

Fig. 2. Photographs showing the stability of St monomer emulsions prepared with the polymeric surfactant $\left(A ; S_{0}=1.25 \mathrm{~g} / \mathrm{dm}^{3}\right.$ water, $\left.B ; S_{0}=10 \mathrm{~g} / \mathrm{dm}^{3}\right)$ and with SDS (C; $S_{0}=1.25 \mathrm{~g} / \mathrm{dm}^{3}, \mathrm{D} ; S_{0}=10 \mathrm{~g} / \mathrm{dm}^{3}$ )

\section{Stability of monomer emulsion}

Emulsification of St monomer with conventional low-molecular-weight surfactants usually results in a considerably coarse monomer emulsion, where monomer droplets easily coalesce within a few minutes when stirring is stopped. The monomer emulsion made with the polymeric surfactant greatly increased emulsion stability compared with that prepared with a conventional surfactant, SDS. Fig. 2 shows photographs comparing the stability of St monomer emulsions made with the polymeric surfactant and SDS, respectively, left standing for $1 \mathrm{~h}$ after stirring was stopped. Stirring speed was $200 \mathrm{rpm}$. The surfactant concentrations used were $S_{0}=$ 1.25 and $10 \mathrm{~g} / \mathrm{dm}^{3}$ water, respectively, the St concentration being kept at $M_{0}=0.20$ $\mathrm{g} / \mathrm{cm}^{3}$ water. The monomer emulsions made with SDS (C: $1.25 \mathrm{~g} / \mathrm{dm}^{3}$ and D: 10 $\mathrm{g} / \mathrm{dm}^{3}$ ) began to separate into two phases with a creamed monomer layer and an almost clear aqueous solution as soon as stirring was stopped, even when the emulsifier concentration was $10 \mathrm{~g} / \mathrm{dm}^{3}$ (D). However, the monomer emulsion made even with a lower concentration of the polymeric surfactant such as $1.25 \mathrm{~g} / \mathrm{dm}^{3}(A)$ did not separate at all on standing for $3 \mathrm{~h}$, appearing to be uniform. Furthermore, optical microscopy revealed that the diameter of St emulsion droplets made with the polymeric surfactant was in the range of several $\mu \mathrm{m}$, which is much smaller than of those made with SDS surfactant.

It is now well accepted that in St emulsion polymerization containing emulsifier micelles and initiated by water soluble initiators, negligible initiation takes place in the monomer droplets, and that the dominant site of initiation is limited to the monomer- 
swollen micelles capturing oligomeric radicals from the water phase. Negligible nucleation in the monomer droplets has been ascribed to smaller surface areas of the monomer droplets as compared to those of the micelles. As described above, the monomer emulsion droplets prepared by using the polymeric surfactant are of very small size and have large surface areas. Therefore, this suggests us a possibility that the very fine monomer droplets produced in this system could capture oligomeric radicals from the water phase to become polymer particles as in the case of miniemulsion polymerizations.

\section{Effect of stirring rate}

The effects of stirring rate on the course of the emulsion polymerization of St conducted with the polymeric surfactant as emulsifier were first examined experimentally. The initial emulsifier, initiator and monomer concentrations were fixed at $S_{0}=10$ $\mathrm{g} / \mathrm{dm}^{3}$ water, $I_{0}=1.25 \mathrm{~g} / \mathrm{dm}^{3}$ and $M_{0}=0.2 \mathrm{~g} / \mathrm{cm}^{3}$, respectively. Fig. 3 shows the conversion versus time histories observed when stirring rate was varied from 100 to 400 rpm. All experiments proceeded very smoothly without any trace of coagulum over the whole range of stirring rate investigated.

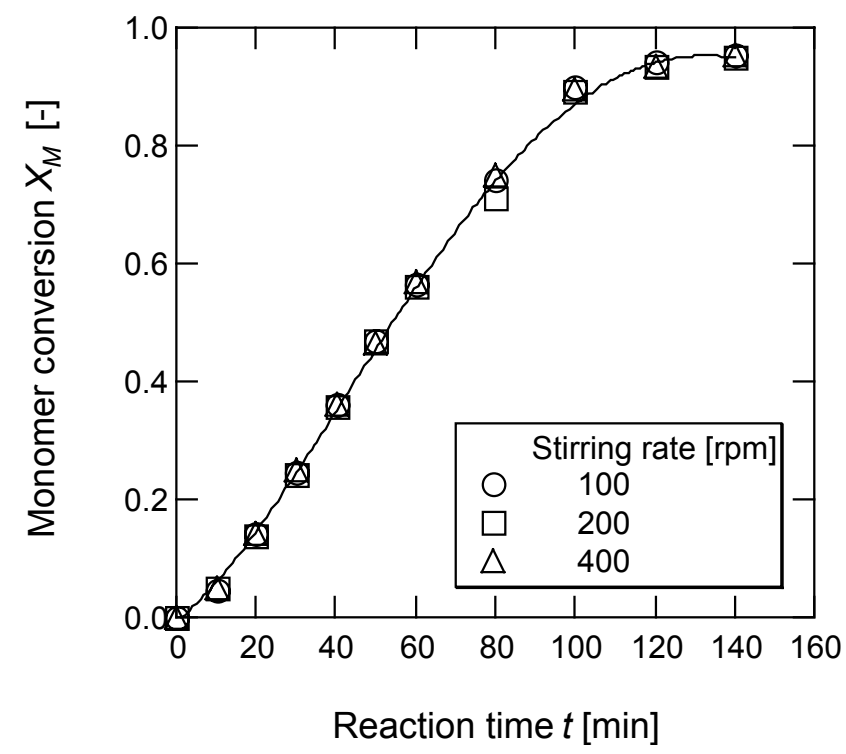

Fig. 3. Effect of stirring rate on the course of the emulsion polymerization of St in water conducted with initial polymeric surfactant, initiator and monomer concentrations $S_{0}=10$ $\mathrm{g} / \mathrm{dm}^{3}, I_{0}=1.25 \mathrm{~g} / \mathrm{dm}^{3}$ and $M_{0}=0.20$ $\mathrm{g} / \mathrm{cm}^{3}$

On the other hand, Fig. 4 shows the number of polymer particles produced versus the monomer conversion observed when stirring rate was increased from100 to 400 rpm. The average particle diameter in the final polymer latex $\left(X_{M}>0.95\right)$ is about 100 $\mathrm{nm}$ irrespective of stirring rate. Both the number of polymer particles produced and the rate of polymerization were found not to be affected at all by the degree of stirring as long as the stirring rate was in this range. If this polymerization proceeded according to the mechanism of mini-emulsion polymerization, the number of polymer particles produced could be expected to change because strong stirring rate would produce smaller monomer droplets and, hence, a larger number of monomer droplets, most part of which would finally become polymer particles. Considering that the stirring rate did not affect the number of polymer particles produced, however, one can safely regard that this polymerization system does not proceed according to the mechanism of mini-emulsion polymerization. 


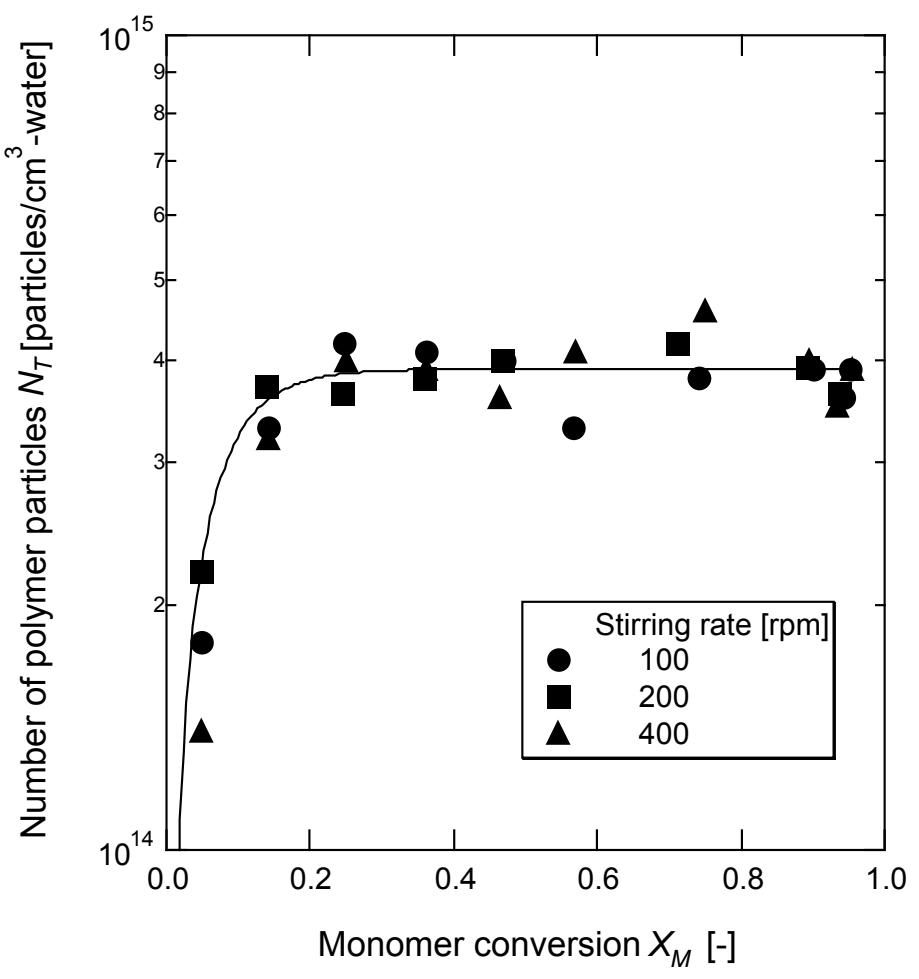

Fig. 4. Effect of stirring rate on the number of polymer particles produced versus monomer conversion (conditions correspond to Fig. 3)

\section{Effect of initial emulsifier concentration}

Fig. 5 shows the effect of emulsifier concentration initially charged on the monomer conversion versus time histories, which was observed when the initial initiator and monomer concentrations and the stirring rate were fixed at $I_{0}=1.25 \mathrm{~g} / \mathrm{dm}^{3}$ water, $M_{0}$ $=0.20 \mathrm{~g} / \mathrm{cm}^{3}$ and $200 \mathrm{rpm}$, respectively. The initial emulsifier concentration $S_{0}$ was varied more than 100 times from 0.313 to $40 \mathrm{~g} / \mathrm{dm}^{3}$. It is obvious that the rate of polymerization increases with increasing emulsifier concentration. When the initial emulsifier concentration was higher than $5 \mathrm{~g} / \mathrm{dm}^{3}$ water, the polymerization proceeded very smoothly without any coagulum formation up to the conversion where polymerization was almost completed. However, when the initial emulsifier concentration was less than $2.5 \mathrm{~g} / \mathrm{dm}^{3}$, the rate of polymerization progressively decreased with gradual formation of coagulum during the polymerization.

The variation of the number of polymer particles produced with the progress of polymerization corresponding to the experiments shown in Fig. 5 is presented in Fig. 6 . When the initial emulsifier concentration is higher than $5 \mathrm{~g} / \mathrm{dm}^{3}$ water, it is obvious from Fig. 6 that the number of polymer particles produced increases with monomer conversion and reaches a constant value at least at about $30 \%$ conversion. Moreover, it seems that the period of polymer particle formation is prolonged with increasing emulsifier concentration. When the initial emulsifier concentration was less than $2.5 \mathrm{~g} / \mathrm{dm}^{3}$, the number of polymer particles reached a constant value in a relatively early stage of the polymerization, independently of the emulsifier concentration. Considering that the number of polymer particles reached a constant value from the very beginning of the polymerization when SDS was used in the emulsion polymerization of St [17], these experimental results suggest that the mechanism of particle nucleation occurring in the systems with polymeric surfactant as emulsifier may be somewhat different from that in the emulsion polymerization of St with SDS as emulsifier, even though the main source of polymer particles produced in this system is micelles. 


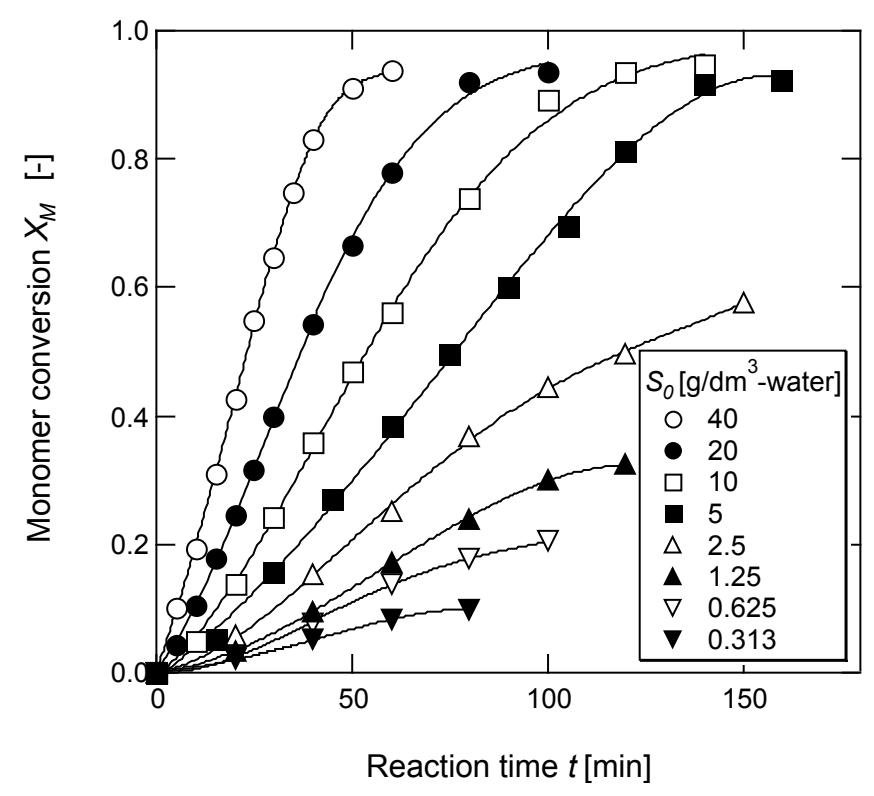

Fig. 5. Effect of initial emulsifier concentration on the course of emulsion polymerization of St with initiator and monomer concentrations fixed at $I_{0}=1.25 \mathrm{~g} / \mathrm{dm}^{3}$ and $M_{0}=$ $0.20 \mathrm{~g} / \mathrm{cm}^{3}$

Fig. 6. Effect of the initial emulsifier concentration on the number of polymer particles produced versus monomer conversion corresponding to Fig. 5

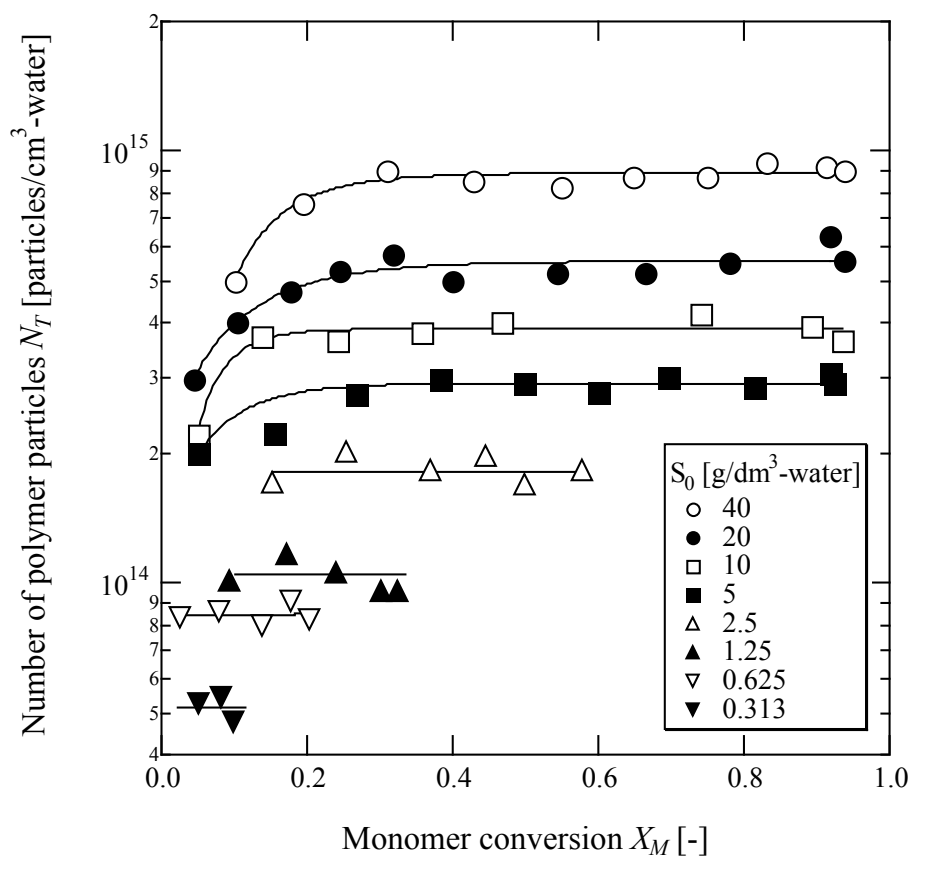

Each constant particle number presented in Fig. 6 is replotted in Fig. 7 against the corresponding initial emulsifier concentration charged, along with the rate of polymerization calculated from the slope of the linear portion $\left(0.10<X_{M}<0.40\right)$ of the conversion versus time curves shown in Fig. 5 . From these plots, it is concluded that both the number of polymer particles produced and the rate of polymerization increase with increasing emulsifier concentration and are proportional to the 0.6 power of the initial emulsifier concentration. This exponent is in good agreement with the value predicted by the Smith-Ewart theory [19] and also with that obtained by Harada et al. [17], who used SDS as emulsifier in the emulsion polymerization of St.

On the other hand, it is well known that the number of polymer particles produced decreases drastically in the vicinity of CMC when the emulsion polymerization of sparingly water-soluble monomers such as St is carried out by using conventional emulsifiers such as SDS [17]. However, the number of polymer particles produced in 
systems with this polymeric surfactant as emulsifier decreased monotonically even to $S_{0}=0.313 \mathrm{~g} / \mathrm{dm}^{3}$ water, which is much lower than the CMC of SDS $\left(0.5-0.7 \mathrm{~g} / \mathrm{dm}^{3}\right.$ at $I_{0}=1.25 \mathrm{~g} / \mathrm{dm}^{3}$ of KPS [17]). The reason for this will be that the CMC of this polymeric surfactant (c. $0.1 \mathrm{~g} / \mathrm{dm}^{3}$ as shown in Fig. 1) is far lower than that of SDS.

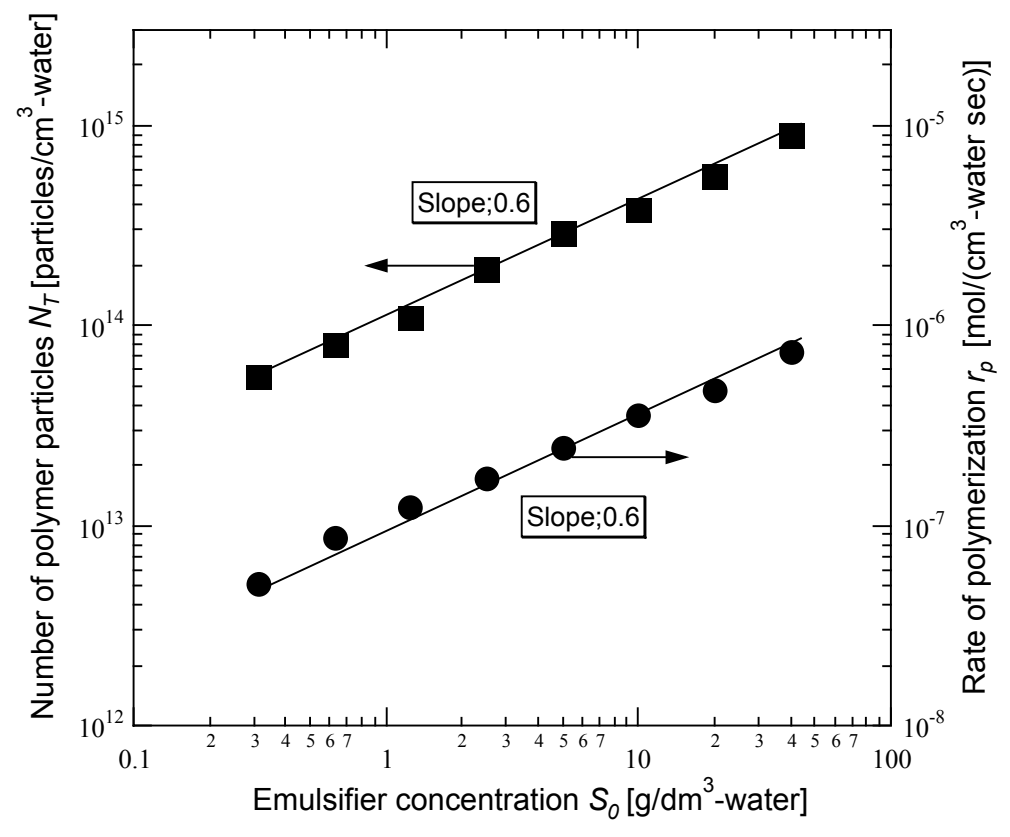

Fig. 7. Dependence of the rate of polymerization and of the number of polymer particles produced on the initial polymeric surfactant concentration determined by using the data obtained from Figs. 5 and 6

\section{Effect of initial initiator concentration}

In these polymerization experiments, the initial initiator concentration $I_{0}$ was varied from 0.313 to $5.0 \mathrm{~g} / \mathrm{dm}^{3}$ water, while the initial emulsifier and monomer concentrations were fixed at $S_{0}=10 \mathrm{~g} / \mathrm{dm}^{3}$ and $M_{0}=0.20 \mathrm{~g} / \mathrm{cm}^{3}$, respectively. Fig. 8 shows the effect of the initial initiator concentration on the course of polymerization. The variation of the number of polymer particles produced with the monomer conversion corresponding to the experiments shown in Fig. 8 is presented in Fig. 9. It is seen that polymerization proceeds very smoothly to almost completion and that the number of polymer particles produced becomes constant around $20 \%$ conversion. However, when the initial initiator concentration was higher than $2.5 \mathrm{~g} / \mathrm{dm}^{3}$, both the polymerization rate and the number of polymer particles began to decrease from somewhere above $40 \%$ conversion. The reason may be as follows. When the initial initiator concentration is increased, the number of polymer particles produced increases and, hence, the total surface area of polymer particles also increases. However, the amount of the polymeric surfactant adsorbed per unit surface area of particles decreases with increasing number of polymer particles because the initial emulsifier concentration is fixed. In addition, high electrolyte (KPS) concentration in the water phase decreases the effective surface charges on the resultant polymer particles and, hence, the polymer particles become unstable against coagulation. Thus, gradual coagulation with time finally resulted in massive coagulates and fouling, which made further stirring difficult.

Both the rate of polymerization obtained from the linear portion $\left(0.10<X_{\mathrm{M}}<0.40\right)$ of the conversion versus time curves and the number of polymer particles produced shown in Figs. 8 and 9 are plotted against the initial initiator concentration in Fig. 10. It is clear from Fig. 10 that both the number of polymer particles produced and the rate of polymerization are proportional to the 0.4 power of the initial initiator concen- 
tration. The value of 0.4 agrees with that predicted by Smith-Ewart theory [19] and is the same as that usually found in the emulsion polymerization of St carried out with SDS as emulsifier [17].

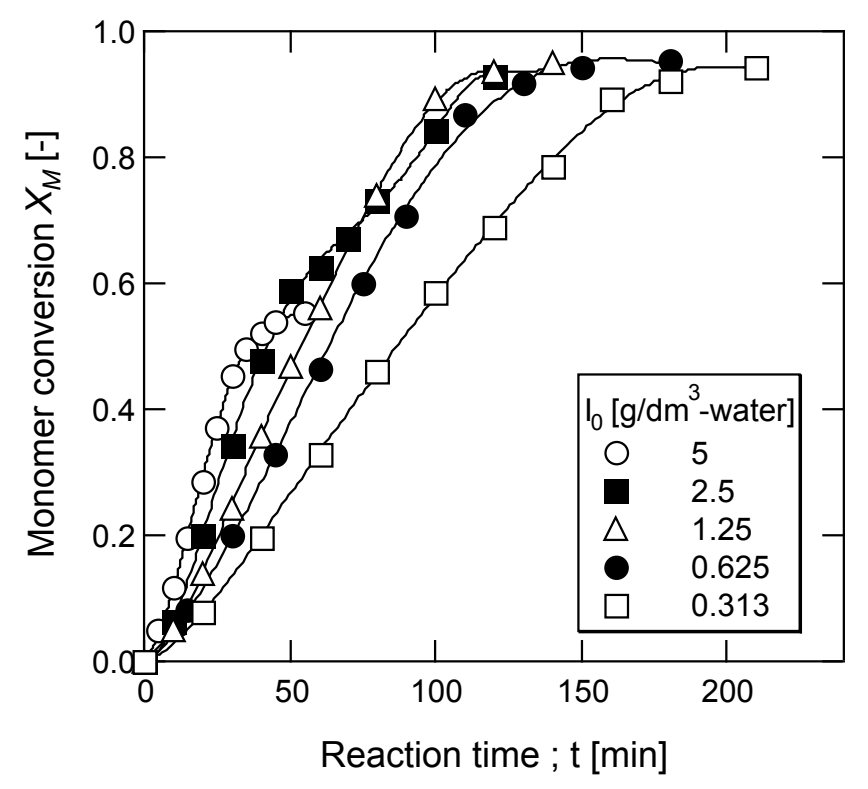

Fig. 8. Effect of initial initiator concentration on the course of emulsion polymerization of St with the polymeric surfactant and monomer concentrations fixed at $S_{0}=10 \mathrm{~g} / \mathrm{dm}^{3}$ and $M_{0}=0.20 \mathrm{~g} / \mathrm{cm}^{3}$

Fig. 9. Effect of initial initiator concentration on the number of polymer particles produced vs. monomer conversion corresponding to Fig. 8

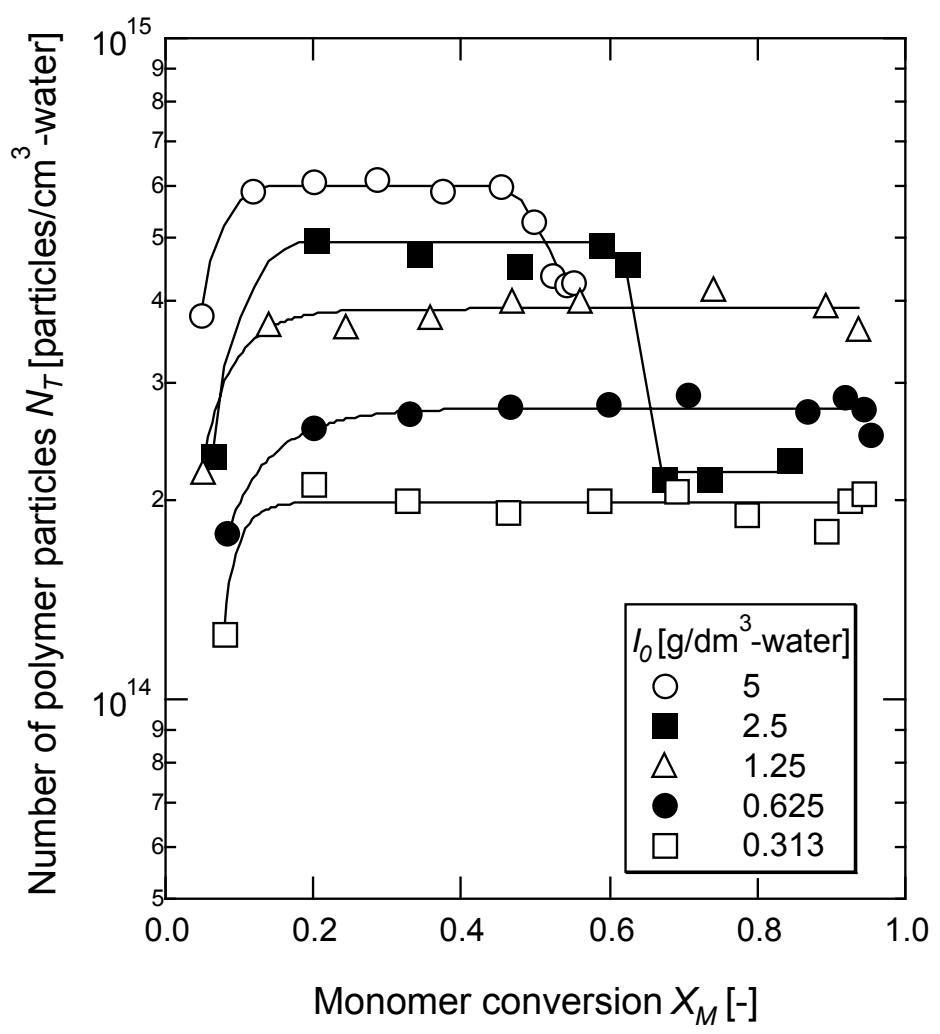

\section{Effect of initial monomer concentration}

The effects of the initial monomer concentration on the course of polymerization and the number of polymer particles produced were examined experimentally. The initial emulsifier and initiator concentrations were fixed at $S_{0}=10 \mathrm{~g} / \mathrm{dm}^{3}$ water and $I_{0}=1.25$ $\mathrm{g} / \mathrm{dm}^{3}$, respectively. The rate of polymerization calculated from the slope of each 
conversion versus time curve is plotted against the initial monomer concentration in Fig. 11 along with the number of polymer particles produced. It is seen that the number of polymer particles produced and the rate of polymerization are both independent of the initial monomer concentration. This result is the same as that observed in the emulsion polymerization of St with a conventional emulsifier such as SDS [17].
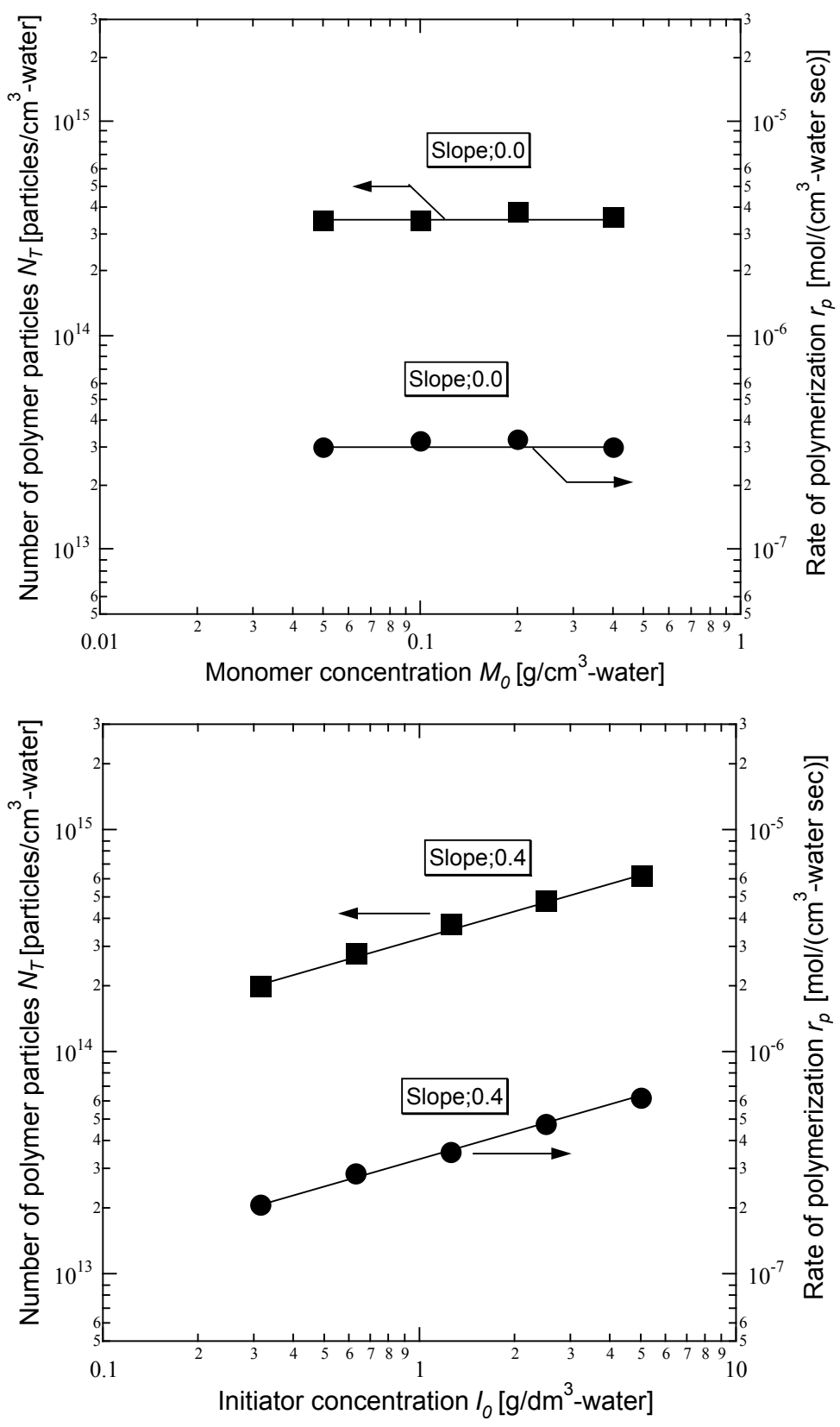

Fig. 10. Dependence of the rate of polymerization and of the number of polymer particles produced on the initial initiator concentration determined by the data obtained from Figs. 8 and 9
Fig. 11. Dependence of the rate of polymerization and of the number of polymer particles produced on the initial monomer concentration (conditions were $S_{0}=10 \mathrm{~g} / \mathrm{dm}^{3}, I_{0}$ $=0.20 \mathrm{~g} / \mathrm{cm}^{3}$ and $50^{\circ} \mathrm{C}$ )

\section{Average number of radicals per particle}

Several researchers [20-23] have pointed out that when polymeric surfactants acting as electrosteric stabilizers were used for emulsion polymerizations, the rate of polymerization was found to decrease due to a decrease in the average number of radicals per particle. This is caused by a decrease in the rate of radical entry into the polymer particles because the hairy layer built up by the adsorbed polymeric surfactant on the surface of the polymer particles could become a diffusion barrier for the 
entering radicals. Therefore, it was checked also in this study whether the same phenomenon could be observed in the emulsion polymerization of St with the polymeric surfactant.

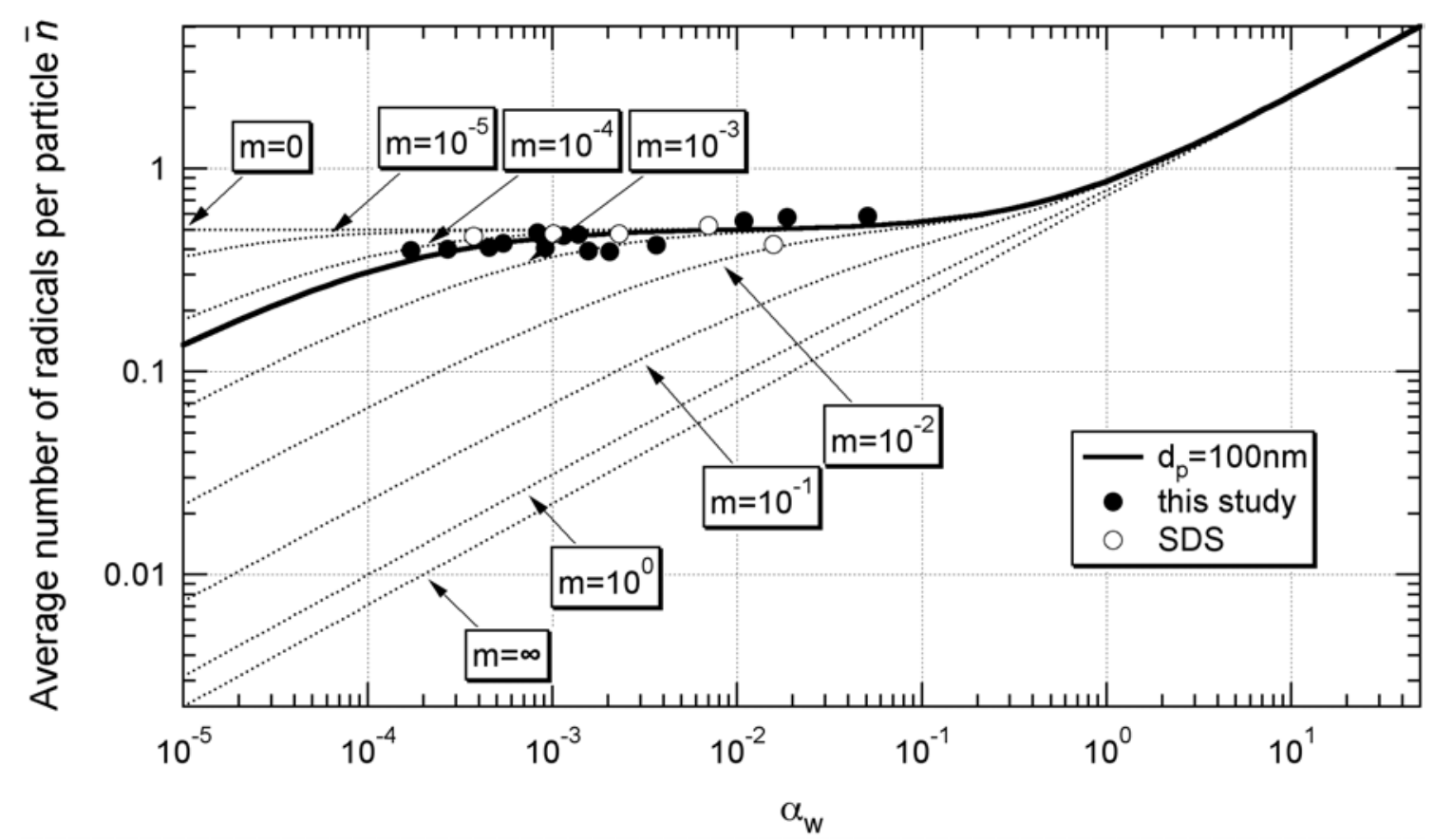

Fig. 12. Comparison of the values of $\bar{n}$ observed in systems with polymer surfactant and with SDS by plotting $\bar{n}$ against $\alpha_{\mathrm{w}}$

The average number of radicals per particle, $\bar{n}$, can be calculated by applying the following well-known polymerization rate equation to the observed monomer conversion versus time curves.

$r_{\mathrm{P}}=\left(\frac{M_{0}}{M_{\mathrm{m}}}\right) \frac{\mathrm{d} X_{\mathrm{M}}}{\mathrm{d} t}=\frac{k_{\mathrm{P}}[M]_{\mathrm{p}} \bar{n} N_{\mathrm{T}}}{N_{\mathrm{A}}}$

where $r_{\mathrm{p}}$ is the rate of polymerization in $\mathrm{mol} /\left(\mathrm{cm}^{3} \cdot \mathrm{s}\right), k_{\mathrm{p}}$ the propagation rate constant, $[\mathrm{M}]_{\mathrm{p}}$ the monomer concentration in the particles, $M_{0}$ the weight of monomer initially charged per $\mathrm{cm}^{3}$ water, $M_{\mathrm{m}}$ the molecular weight of monomer, and $N_{\mathrm{A}}$ Avogadro's number. The values of $\bar{n}$, calculated by applying the data shown in Figs. 7, 10 and 11 to Eq. (2), are plotted against the corresponding value of the parameter $\alpha_{w}$ in Fig. 12 with closed circles. On the other hand, the values of $\bar{n}$ obtained in the emulsion polymerization of St with SDS as emulsifier and KPS as initiator [17] were also plotted with open circles to compare with those obtained in this polymerization system. Furthermore, the broken lines in Fig. 12 show the plots of theoretical values of $\bar{n}$ vs. the values of $\alpha_{\mathrm{w}}$ predicted by the following semitheoretical expression [24]:

$\bar{n}=\frac{1}{2}\left\{\left[\left(\alpha_{w}+\frac{\alpha_{w}}{m}\right)^{2}+2\left(\alpha_{w}+\frac{\alpha_{w}}{m}\right)\right]^{1 / 2}-\left(\alpha_{w}+\frac{\alpha_{w}}{m}\right)\right\}+\left(\frac{1}{4}+\frac{\alpha_{w}}{2}\right)^{1 / 2}-\frac{1}{2}$

where the nondimensional parameters, $\alpha_{\mathrm{w}}$ and $m$, are defined as $\alpha_{\mathrm{w}}=\left(r_{\mathrm{i}} v_{\mathrm{p}} / k_{\mathrm{tp}} N_{\mathrm{T}}\right)$ and $m=\left(k_{\mathrm{f}} v_{\mathrm{p}} / k_{\mathrm{tp}}\right)$, respectively. Here, $r_{\mathrm{i}}$ is the rate of radical production in the water 
phase, $v_{\mathrm{p}}$ the volume of the monomer-swollen polymer particle, $k_{\mathrm{tp}}$ the rate constant for radical termination in the polymer particles, and $k_{\mathrm{f}}$ the rate coefficient for radical desorption from the polymer particles, respectively. The rate coefficient for radical desorption from the polymer particles, $k_{\mathrm{f}}$, is approximately predicted by [24]

$k_{\mathrm{f}}=\frac{12 D_{\mathrm{w}} \delta C_{\mathrm{m}}}{m_{\mathrm{d}} d_{\mathrm{p}}{ }^{2}}$

where $D_{\mathrm{w}}$ is the diffusion coefficient of monomer radicals in the aqueous phase, $m_{\mathrm{d}}$ the partition coefficient of monomer radicals between polymer particle and aqueous phase, $d_{\mathrm{p}}$ the average diameter of polymer particles, $C_{\mathrm{m}}$ the chain transfer constant to monomer, and $\delta$ the ratio of the water side to the overall diffusion resistances for the desorption of monomer radicals from the polymer particle into the water phase. All numerical constants used in this calculation are listed in Tab. 2.

Tab. 2. Values of numerical constants at $50^{\circ} \mathrm{C}$

\begin{tabular}{cccc}
\hline Constant & Value & Unit & Ref. \\
\hline$k_{\mathrm{d}} f$ & $6.7 \cdot 10^{-7}$ & $\mathrm{~s}^{-1}$ & {$[25]$} \\
$k_{\mathrm{tp}}$ & $5.0 \cdot 10^{-15}$ & $\mathrm{~cm}^{3} / \mathrm{s}$ & {$[25]$} \\
$k_{\mathrm{p}}$ & 235 & $\mathrm{dm}^{3} /(\mathrm{mol} \cdot \mathrm{s})$ & {$[26]$} \\
$C_{\mathrm{m}}$ & $1.2 \cdot 10^{-5}$ & - & {$[25]$} \\
$D_{\mathrm{w}}$ & $1.2 \cdot 10^{-5}$ & $\mathrm{~cm}^{2} / \mathrm{s}$ & {$[25]$} \\
$\delta$ & 0.15 & - & {$[25]$} \\
$m_{\mathrm{d}}$ & 1300 & - & {$[25]$}
\end{tabular}

It is seen in Fig. 12 that almost all experimental data points fall on the same solid line, which corresponds to the theoretical line for the polymer particles with $d_{\mathrm{p}}=100 \mathrm{~nm}$. Moreover, it is clear that the values of $\bar{n}$ observed in this study are almost the same as those obtained in the emulsion polymerization of St with SDS as emulsifier [17]. It is concluded from this comparison that the possible diffusion barrier built up by a carboxylated polymeric surfactant adsorbed on the surface of polymer particles is, if any, not necessarily very significant in this case compared to that formed by a conventional electrostatic emulsifier such as SDS, although several researchers have pointed out the phenomenon [20-23].

\section{Conclusions}

A surface-active polyelectrolyte, poly(MMA-co-MAA) was synthesized by semi-batch emulsion polymerization, and its ammonium salt was utilized as polymeric emulsifier for the emulsion polymerization of St. It was clarified by using the pyrene fluorescence method that the polymeric surfactant forms a kind of aggregates like micelles in its aqueous solution at least in the region above $c .0 .1 \mathrm{~g} / \mathrm{dm}^{3}$ water. The monomer emulsion made with the polymeric surfactant was found to be extremely stable with negligible separation on standing for several hours. The size of monomer droplets in the monomer emulsion thus produced was very small, being in the range of several $\mu \mathrm{m}$. The emulsion polymerization of St was carried out at $50^{\circ} \mathrm{C}$ by using the synthe- 
sized polymeric surfactant, ammonium salt of poly(MMA-co-MAA), as emulsifier and KPS as initiator to elucidate the kinetic role of this polymeric surfactant in the emulsion polymerization of St. We clarified that the number of polymer particles produced, $N_{\mathrm{T}}$, and the rate of polymerization, $r_{\mathrm{p}}$, were correlated by the following expressions, which agree well with the predictions by Smith-Ewart theory [19] and are quite the same as those observed in the emulsion polymerization of St conducted with SDS as emulsifier and KPS as initiator, respectively.

$$
\begin{aligned}
& N_{\mathrm{T}} \propto S_{0}^{0.6} \cdot I_{0}^{0.4} \cdot M_{0}^{0.0} \\
& r_{\mathrm{p}} \propto S_{0}^{0.6} \cdot I_{0}^{0.4} \cdot M_{0}^{0.0}
\end{aligned}
$$

[1] Urquiola, M. B.; Dimonie, V. L.; Sudol, E. D.; El-Aasser, M. S.; J. Polym. Sci., Part A: Polym Chem. 1992, 30, 2619.

[2] Urquiola, M. B.; Dimonie, V. L.; Sudol, E. D.; El-Aasser, M. S.; J. Polym. Sci., Part A: Polym Chem. 1992, 30, 2631.

[2] Urquiola, M. B.; Dimonie, V. L.; Sudol, E. D.; El-Aasser, M. S.; J. Polym. Sci., Part A: Polym Chem. 1993, 31, 1403.

[4] Ferguson, F.; Sherrington, D. C.; Gough, A.; Polymer 1993, 34, 3281.

[5] Nagai, K.; Satoh, H.; Kuramoto, N.; Polymer 1993, 34, 4969.

[6] Piirma, I.; Lenzotti, J. R.; Br. Polym. J. 1989, 21, 45.

[7] Jialanella, G. L.; Piirma, I.; J. Appl. Polym. Sci. 1991, 42, 1423.

[8] Jialanella, G. L.; Firer, E. M.; Piirma, I.; J. Polym. Sci., Part A: Polym. Chem. 1992, 30, 1925.

[9] Roe, C. P.; J. Colloid Interface Sci. 1971, 37, 93.

[10] Kuo, P. L.; Chen, C. J.; J. Polym. Sci., Part A: Polym Chem. 1993, 31, 99.

[11] Lee, D. Y.; Kim, J. H.; J. Polym. Sci., Part A: Polym Chem. 1998, 36, 2865.

[12] Makgawinata, T.; El-Aasser, M. S.; Vanderhoff, J. W.; Pichot, C.; Acta Polym. 1981, 32, 583.

[13] Arzamendi, G.; Leiza, J. R.; Asua, J. M.; J. Polym. Sci., Part A: Polym Chem. 1991, 29, 1549.

[14] Kalyanasundaram, K.; Thomas, J. K.; J. Am. Chem. Soc. 1977, 99, 2039.

[15] Ringsdorf, H.; Venzmer, J.; Winnik, F. M.; Macromolecules 1991, 24, 1678.

[16] Winnik, F. M.; Davidson, A. R.; Hamer, G. K.; Kitano, H.; Macromolecules 1992, $25,1876$.

[17] Harada, M.; Nomura, M.; Kojima, H.; Eguchi, W.; Nagata, S.; J. Appl. Polym. Sci. 1972, 16, 811.

[18] Bailey, A. E.; in "Industrial Oil and Fat Products", Interscience, New York 1951, pp. 359.

[19] Smith, W. V.; Ewart, R. H.; J. Chem. Phys. 1948, 16, 592.

[20] Coen, E. M.; Lyons, R. A.; Gilbert, R. G.; Macromolecules 1996, 29, 5128.

[21] Cheong, I. W.; Kim, J. H.; Colloid Polym. Sci. 1997, 275, 736. 
[22] Vorwerg, L.; Gilbert, R. G.; Macromolecules 2000, 33, 6693.

[23] Lee, D. Y.; Kim, J. H.; Min, T. I.; Colloid Surfaces, A: Physicochem. Eng. Asp. 1999, 153, 89.

[24] Nomura, M.; Harada, M.; J. Appl. Polym. Sci. 1981, 26, 17.

[25] Nomura, M.; Kubo, M.; Fujita, K.; J. Appl. Polym. Sci. 1983, 28, 2767.

[26] Gilbert, R. G.; Pure Appl. Chem. 1996, 68,1491. 